Article

\title{
The Dislocation of News Journalism: A Conceptual Framework for the Study of Epistemologies of Digital Journalism
}

\author{
Mats Ekström ${ }^{1, *}$ and Oscar Westlund ${ }^{2}$ \\ ${ }^{1}$ Department of Journalism, Media and Communication, University of Gothenburg, 40530 Gothenburg, Sweden; \\ E-Mail: mats.ekstrom@jmg.gu.se \\ 2 Department of Journalism and Media Studies, Oslo Metropolitan University, 0130 Oslo, Norway; \\ E-Mail: oscar.westlund@oslomet.no \\ * Corresponding author
}

Submitted: 30 November 2018 | Accepted: 11 February 2019 | Published: 21 March 2019

\begin{abstract}
This article focuses on news journalism, social media platforms and power, and key implications for epistemology. The conceptual framework presented is intended to inspire and guide future studies relating to the emerging sub-field of journalism research that we refer to as "Epistemologies of Digital Journalism". The article discusses the dependencies between news media and social media platforms (non-proprietary to the news media). The authority and democratic role of news journalism pivot on claims that it regularly provides accurate and verified public knowledge. However, how are the epistemic claims of news journalism and the practices of justifications affected by news journalism's increased dependency on social media platforms? This is the overall question discussed in this article. It focuses on the intricate power dependencies between news media and social media platforms and proceeds to discuss implications for epistemology. It presents a three-fold approach differentiating between (1) articulated knowledge and truth claims, (2) justification in the journalism practices and (3) the acceptance/rejections of knowledge claims in audience activities. This approach facilitates a systematic analysis of how diverse aspects of epistemology interrelate with, and are sometimes conditioned by, the transformations of news and social media.
\end{abstract}

\section{Keywords}

digital journalism; dislocation; epistemology; news journalism; platform companies; power dependency; social media platforms

\section{Issue}

This article is part of the issue "Journalism and Social Media: Redistribution of Power?", edited by Marcel Broersma and Scott Eldridge II (University of Groningen, The Netherlands).

(C) 2019 by the authors; licensee Cogitatio (Lisbon, Portugal). This article is licensed under a Creative Commons Attribution 4.0 International License (CC BY).

\section{Introduction: Epistemologies of Digital Journalism}

This conceptual article focuses on the relationships between news journalism, social media platforms, power dependencies and epistemology. It aims to conceptualize and critically discuss dislocation of news journalism, and key implications for epistemology of a disrupted 'established order' surrounding news. Dislocation of news journalism comprises a series of parallel developments regarding shifting power dependencies between the news media and platform companies.
A platform is a digital infrastructure with affordances offering diverse kinds of information and communication, as well as opportunities to produce, publish and engage with content. Platform companies do not produce and publish content themselves, and thus do not define themselves as publishers. Instead they operate with a business model in which they provide a digital platform on which individuals and institutions can communicate and publish information (e.g., Gillespie, 2018). They are oftentimes referred to as digital intermediaries because they succeed in establishing themselves 
between citizens/consumers/producers and diverse organizations. More specifically, dislocation of news journalism includes a displacement of power for news producers having less control over publishing contexts when news stories are detached from the context in which they were originally embedded by the news organization (Carlson, 2017, p. 65). The article acknowledges the crucial importance of more general shifts in revenue from news media firms to platform companies, and more specific shifts such as distinct actors having gained power concerning gathering, analyzing and selling data and analytics that become interwoven with how editorial decisions are made (cf. Carlson, 2018a; Zamith, 2018). However, we will focus exclusively on aspects of dislocation with key implications for news epistemology.

By introducing this conceptual framework we intend to make a scholarly contribution to research in journalism studies (Carlson, Robinson, Lewis, \& Berkowitz, 2018; Steensen \& Ahva, 2015), and more specifically to the emerging field of digital journalism studies (e.g., Eldridge \& Franklin, 2017, 2019; Robinson, Lewis, \& Carlson, in press). This could bridge continuums involving "change" and "continuity" as well as "digital" and "journalism" in engaging the field (Eldridge, Hess, Tandoc, \& Westlund, in press; Steensen, Larsen, Hågvar, \& Fonn, in press). Moreover, we contribute to research on epistemology (cf. Ekström \& Westlund, 2019). While there are examples of thematic coordination of such research (e.g., Van Leuven, Kruikemeier, Lecheler, \& Hermans, 2018), research contributing to contemporary knowledge about epistemology sometimes presents its contribution in other terms. We argue there is good reason to consider much of this research as contributing to an emerging subfield of research which we call: "Epistemologies of Digital Journalism".

We write "epistemologies" with the explicit intention to connote plurality; there are several different epistemologies for different genres and forms of journalism. Classic TV-broadcasting journalism has its epistemologies (Ekström, 2002), as does live blogging (Matheson \& Wahl-Jorgensen, in press; Thorsen \& Jackson, 2018), participatory journalism (Anderson \& Revers, 2018; KliglerVilenchik \& Tenenboim, in press), data journalism (Lewis \& Westlund, 2015a), the more distinct structured journalism (Graves \& Anderson, in press), and emerging forms of automated journalism (Carlson, 2018b). Having said this, journalism also comes with important similarities across its genres and forms, in working towards reporting worthwhile and verified information about important events.

In line with classical works on power and dependence (Emerson, 1962), we distance ourselves from exercises treating power as an attribute of a person or company. We share the view that "power is a property of the social relation, instead of an attribute of the actor" (Emerson, 1962 , p. 32). Emerson has proposed a theory of powerdependence relations, originally growing out of relationships between social actors and groups, which can be applied to how we understand industry actors (i.e., compa- nies). Emerson argues that a salient indicator of power concerns how actor I depends on actor II for achieving their set goals. This article brings similar attention to the more general dependencies between news media organizations and their proprietary platforms on the one hand, and social media companies and their platforms (nonproprietary to the news media) on the other (cf. Westlund \& Ekström, 2018). Such dependencies relate to audience reach and revenue, and to the epistemic goals and claims news journalism tries to achieve. Thus, it is essential to study contemporary processes of dislocation from publishers to platform companies, alongside publishers' attempts to counterbalance those processes by strategic initiatives intended for regaining control and power.

Research into epistemologies of digital journalism over the past decade has suggested that the authority and democratic role of news journalism pivot on claims that it regularly provides accurate and verified public knowledge (Carlson, 2017). Truth claims are manifest in the professional norms of truth-telling (Karlsson, 2011) and in the discursive constructions of factuality in news texts (Montgomery, 2007). Truth claims are justified in practices of professional news production and evaluated, accepted or rejected in the practices of news consumption. Yet, how are the epistemic claims of news journalism and the practices of justifications affected by news journalism's increased dependency on social media platforms?

The democratic role and authority of news journalism depends on being able to reach out to citizens who engage in news consumption to become informed. However, transformations within professional journalism and how news organizations and consumers depend on social media have resulted in an increasingly complex situation; social media have exercised complementary, displacing and even replacing effects on various aspects of journalism. This has affected diverse aspects of journalism, notably business and epistemology. Ultimately, different forms of power gained by social media platforms extend far beyond securing a strong position in global markets, towards becoming a "normalized" part of the operations of diverse companies and the everyday life of citizens worldwide. Social media platforms have indeed gained significant influence as to the overall role journalism and news play in democracy. They have converged with news media's digital platforms and operations, and are both partners and catalysts to the news media (enabling new epistemic practices such as sourcing, new distribution techniques and analytics, and new context for audiences' verification and authorization of news), as well as fierce and harmful competitors (encroaching on "attention time", data, and advertising expenditures).

Over the past decade, the intersection of social media and journalism has been amply studied. Studies argued that the web and social media enabled the production of news that may contribute to richer knowledge and more diverse perspectives, while providing distributed fact checking. Others have argued that social media will be a "net positive" that "reflects real- 
ity" and "matters over and above other factors" (Lewis \& Molyneux, 2018). Such work approached social media platforms in positive ways, uncritically associating success with achieving traffic and engagement on social media platforms, and possibly routing some of this engagement success back to their proprietary digital platforms (e.g., websites, or apps). While research initially approached the web and social media with a high level of optimism about its potential for participation and enhancing democracy (Borger, van Hoof, Costera Meijer, \& Sanders, 2013), many have taken a sharp turn since, now emphasizing "dark participation", as misinformation and manipulation have gained prominence (Quandt, 2018). Taking this turn, scholars have been encouraged to study how social media platforms disrupt and challenge the news media industries (e.g., Westlund \& Ekström, 2018), and how journalists may develop distinct speech acts and rhetorical strategies in publishing news on social media such as Facebook (Hågvar, 2019). The next section further discusses and problematizes such dislocation from news media to platform companies, addressing production, distribution and consumption aspects.

\section{Dislocation of News Journalism: Shifting Dependency on Platform Companies}

Dislocation refers to a fundamental transformation and disruption of an established order. This article posits the dislocation of news journalism, as involving parallel processes of power redistribution from the news media to platform companies. Power dependencies form the key issue in the transforming relationship between these two industry actors, each of which represent many discrete companies. In the previous mass media era, journalists in few news media organizations produced and published news material in a medium the news publisher they worked for owned and controlled (i.e., proprietary to the news media), for a wide audience. The web has disrupted the media industry, substantially reducing barriers for new entrants to publish themselves (albeit few manage to become significant players). The contemporary digital mediascape involves numerous news producers. Some of them switch between human and computational production and distribution of personalized news content for their own platforms (Lewis \& Westlund, 2015b; Westlund, 2011), and algorithmic-oriented curation on non-proprietary (to the news media) platforms such as Facebook (DeVito, 2017). As Bell, Owen, Brown, Hauka and Rashidian (2017, p. 9) note, "technology platforms have become publishers in a short space of time, leaving news organizations confused about their own future." Many news publishers have since long broadened their portfolio of proprietary platforms, and extended to non-proprietary platforms like mobile ecosystems and social media platforms (Westlund, 2011). Digital innovation takes place continuously, but also because of critical incidents that challenge news practices (Konow-Lund, Hågvar, \& Olsson, 2018).
This signals a general shift from a monopolistic situation involving institutional news producers, to a situation in which news and other forms of information are produced and distributed by a larger diversity of actors, including ordinary citizens (Deuze \& Witschge, 2017). Journalism and its boundaries are being contested in different ways, and defended through professional control (Lewis, 2012), various forms of boundary work (Carlson \& Lewis, 2015) and meta-journalistic discourse (Carlson, 2016). Some "news" producers deliberatively skew the news according to specific political and/or economic interests (Tandoc, Lim, \& Ling, 2018). There are also diverse sets of "alternative media" applying somewhat similar and somewhat dissimilar news production routines (Holt, 2018). Such social actors do not depend on being published within the realms of news publishers, and the way they control and restrict participatory journalism. They have their own publishing channels. In contrary, we focus exclusively on news media producers organized as a company, employing several journalists, producing and publishing news on a daily basis, taking legal and editorial responsibility for the news content, and operating with at least one proprietary platform (i.e., television, radio, newspaper, news site, news application, which they control).

Social media companies are known as platform companies because they have developed a computing architecture that sets the stage for different social actors to communicate, exchange information, conduct business, etc. Most powerful is Facebook, which also owns Instagram and WhatsApp, and acts as an intermediary between its massive user bases and a plethora of companies which have become increasingly dependent on it. A Tow center report eloquently writes of news media having become a "platform press", as platform companies "have evolved beyond their role as distribution channels, and now control what audiences see and who gets paid for their attention, and even what format and type of journalism flourishes" (Bell et al., 2017, p. 9).

Platform companies operate with a different business model and technological architecture than news media. Social media platforms offer a multitude of affordances, including different forms of one-to-one and one-to-many communication, as well as producing, publishing, accessing, sharing, and engaging with different kinds of information and news such as text, video, audio or data. They typically offer these without a monetary charge. Instead, their revenue model builds on collecting and analyzing data on users' digital footprints and subsequently selling this to advertisers. News publishers also engage in such practices, using data for data-driven journalism. Their dependency on platform companies is evident in their use of algorithms to facilitate personalized news delivery, as news is increasingly distributed in social media platforms that employ algorithms to personalize story selections within users' news feeds (DeVito, 2017).

Social media platforms have built a successful business model; altogether, they have attracted billions of 
people to visit their platforms, securing highly desired attention spans and pulling advertising expenditures from their competitors, including news media companies. The shift in revenue streams is a disruptive and central aspect of the existing power dependencies as news media industries have lost tremendous revenues competing with platform companies, mostly to Facebook and Google. With superior skills, methods and systems for measuring their massive user bases, including for personalizing advertising, platform companies have outcompeted the news media in the advertising market, and have also started competing in the classifieds market which previously benefited news media. News publishers are, as a result, struggling with the business of journalism (Ohlsson \& Facht, 2017; Picard, 2014). Myllylahti (2018) concludes that Facebook has created an "attention economy trap" in which it generates traffic, but not revenue.

There are many ways in which the power-dependence between news media and platform companies has become salient-in the Apple ecosystem, Apple both controls applications and takes nearly one-third of revenues, or with Facebook, with Instant articles in the past, and building paywalls for news publishers inside Facebook in the present. Research into how news publishers relate to and depend on platform companies have begun emerging in recent years. A case study by Nielsen and Ganter (2018) found publishers struggling to balance operation opportunities offered in the short-term, and becoming too dependent on digital intermediaries (i.e., platform companies) in the long-term. In another qualitative study involving case studies from Finland, France, Germany, Italy, Poland, and the United Kingdom, Sehl, Cornia and Nielsen (2018) find public service broadcasters all have dedicated yet small teams working on increasing their reach via social media platforms to drive traffic to their own proprietary news sites, focusing especially on reaching hard-to-reach audiences (especially youth). Some also work towards stimulating user participation. These PSBs have begun consolidating what social media platforms they actively work with. By comparison, the report on the platform press by Bell et al. (2017) shows how some news publishers share news content across a very large number of non-proprietary platforms. Moreover, a longitudinal study of how media workers in two Singaporean news publishers have approached, and made sense of, emerging technologies found "platform counterbalancing", a strategic response where publishers seek to reduce overreliance on non-proprietary social media platforms by instead developing their own portfolio of platforms (Chua \& Westlund, 2019). Acknowledging the tremendous power platform companies have gained, scholars of so-called platform studies have developed a critical and quickly growing body of research on the role of platforms and their logics and economics (Andersson Schwarz, 2017).

Ultimately, the social and networked infrastructures of some platform companies have become interwoven with the operations of news media (Bell et al., 2017;
Bruns, 2018). Although their approaches vary, many news media have felt pressured to develop a social media presence (Chua \& Westlund, 2019; Nielsen \& Ganter, 2018), in some cases resulting in disruption (Wu, 2018). Bruns (2018) argues that professional journalism nowadays is being normalized into social media platforms (controlling the numerous ways in which the public can engage with the news) instead of the other way around. News media firms have turned to platform companies to increase their overall traffic, have appropriated functions that enable users to share news on social media platforms and interact with the news, and have engaged in social media optimization (SMO)-similar to search engine optimization for search-for generating as much traffic volume as possible. Furthermore, news organizations have hired social media editors who actively adapt their news content to publish it on a diverse set of non-proprietary social media platforms. These editors continuously oversee the flow of news being published, and then select, edit, and publish what they consider appropriate (read 'sharable') for publishing on the news media's social media accounts on nonproprietary platforms.

The volume of referral traffic comprises a strong indicator of the role platform companies play. For many years, Facebook gained significance as a source of referral traffic to the news media. However, since mid2017 and in early 2018 the company has shifted its strategy and instead tried to offer a platform that keeps its users on their site and applications. Consequently, the relative proportion of referral traffic from Facebook has decreased substantially (Benton, 2018). What does this reveal concerning dislocation and power dependency? For several years, the news media developed activities aimed at achieving increasingly more traffic (referrals) via social media platforms. A mutual dependency evolved, albeit increasingly marked by tens of thousands of publishers becoming more dependent on one platform company (i.e., Facebook). For Facebook the dependency is salient in cases where users expect news on their platform, and when other forms of similarly appreciated content do not flow in. With these changes Facebook has reduced their already relatively small dependency on news publishers even further, which came as a massive blow to the news industry. As a result, news media firms need to reconfigure their business model and work towards becoming less dependent on non-proprietary platforms, yet maintaining a balanced presence.

The shifting power dependencies for distribution naturally extend to news consumption. Over the past decade, a handful of platform companies have gained significance as key gateways for how people access the news (Newman, Fletcher, Kalogeropoulos, Levy, \& Nielsen, 2018). So-called incidental news discovery via social media has become a salient characteristic of the public's contemporary news consumption (Kim, Chen, \& Gil De Zúñiga, 2013; Newman et. al 2018), although patterns naturally vary between different groups in society. 
However, different news consumption patterns mean very different dependencies on social media. Individuals may stumble upon a relevant news article on the news feed, and digest what is immediately available on their platform. They may click on a link and be directed to a news site, and then immediately return. A third scenario involves the user being redirected from social media to a proprietary news site, where the individual discovers other relevant news articles, and thus becomes more engaged with proprietary news content. When people are gratified from their experiences with a news site, they are presumably also more likely to return to that site to further discover and digest news. This can result in building loyalty and an inclination towards paying for news, whilst reducing dependency on platform companies.

Yet Emerson (1962) argues that a critical aspect of power concerns actors' dependency on another actor for achieving their goals. Facebook and the news media have developed this sort of dependence on each other in building traffic around news content. As many citizens have developed routines of accessing their news via social media, this has displaced some of their former routines. Then, as Facebook diversifies its news feeds, it further reduces its dependency on news content and publishers. Consequently, news publishers who depended significantly on social media for their content to be widely accessed now face problems, and members of the public counting on being fed news via their Facebook feed will also be less exposed to news in such a way.

\section{Dislocation of News Journalism: Epistemic Implications}

The dislocation of news has considerable implications for news epistemology; that is, the forms of knowledge news journalism claims to provide, and how such knowledge is produced, validated and justified (Ekström \& Westlund, 2019). To discuss how news, as relatively authoritative knowledge about the world, is changing in the context of social media, we hereby propose and discuss three central dimensions of news epistemology. The first dimension focuses on the articulation of truth claims in news texts and meta-discourse, the second on how news is produced, validated and justified by journalists, and the third on how news is received and validated by audiences. Related distinctions have been suggested in the literature on journalism culture and epistemology (Hanitzsch, 2007). Our conceptualization of epistemologies is distinctive in its discursive and sociological foundation, focusing on the actual articulation of truth claims in news discourses and the validation of news in social practices, rather than general ideas and philosophical debates such as the one on objectivity.

\subsection{The Articulation of Truth Claims}

A significant aspect of news as a form of knowledge is the articulation of truth claims. The claims of provid- ing verified and reliable news on a daily basis have discerned professional journalism from other forms of public information. This is what most news organizations promise to achieve. Such epistemic claims are articulated in meta-discourses as well as in the conventional forms and language of news (Ekström, 2002). As Carlson (2017, p. 73) argues, "news forms are laden with epistemological premises that shape the type of knowledge they communicate and, by extension, contain an argument for their legitimation." In news discourse, truth-telling is typically shaped by the discursive constructions of factuality, constructions of out-there-ness, disguise of uncertainties, visuals indexing a reality to be taken for granted, the representation of reliable sources of information, forms of quoting and the formal neutral voice of news presenters (Ekström \& Westlund, 2019; Montgomery, 2007, pp. 33,64$)$. This is not to suggest that the epistemic claims of news are homogenous. They vary across subgenres of news journalism. Interpretive, speculative and explicitly partisan news reporting-challenging the restrictions of impartiality-have, for example, been analyzed in several studies (Hutchby, 2011; Salgado \& Strömbäck, 2012). Ultimately, how do the processes of dislocation affect the articulated truth claims of news journalism? Without claiming to be exhaustive, we identify three significant ways.

First, the knowledge and truth claims of news are refashioned in the context of online and social media. A key mechanism concerns the speed with which news is distributed, sometimes going viral via social media, often in the form of "decontextualized snippets of information" (Nielsen, 2017, p. 93). This puts pressure on journalists and the news media to continuously keep apprised as to how events are unfolding. Typically, they consider it important to quickly publish the first version reporting on the news, and to distribute this on both proprietary and non-proprietary platforms. The general claims in news journalism of being fast and first are thus adapted to the temporalities of online and social media (Usher, 2018). Furthermore, social media have enabled the entry of new forms of journalism articulating different knowledge claims. In live blogging, the authoritative voice of the journalist is, for example, reformulated into the role of a "curator" prioritizing and disseminating "bite-sized" and frequently updated information from different sources (Thurman \& Walters, 2013). To some extent, the dislocation of news in social media platforms might contribute to a shift in truth-telling towards more provisional, corrected and even contradictory facts. However, so too is the renewal of evidence and constructions of factuality, such as when screenshots of Twitter and Facebook accounts are provided to show what actors actually say and do, instead of the news referring to sources in quotes and reported speech ("The president said that..."). How these various tendencies manifest in different cultural contexts remains to be investigated in systematic comparative research. This distribution of news in social media, characterized by, not only, a diversity of genres and voices, but 
a crossing and blurring of boundaries between marketing, personal opinions, professional commentaries and impartial news (Lewis \& Molyneaux, 2018), can result in role conflicts for news journalists articulating opinions on personal profiles, adapting to the discursive norms in social media. However, this also likely results in truth claims articulated in the reporting and commenting on specific news events becoming increasingly mixed.

Second, there is a tendency towards obscuring truth claims. Claims refer to the authority of the principal source behind the news and the context of production indicated through diverse institutional markers. The dislocation of news journalism, however, means less control for news producers over the publishing context as news becomes increasingly detached from the original principle and context of production. To explicate, when institutional news media firms publish news for their proprietary platforms, they can set the context of specific information through markers, such as their overall brand. They also determine whether it is analysis, breaking news, editorial, chronicle, and so forth. Such contextual information may be lost when news is published or redistributed on social media platforms. What the news claims to provide in terms of verified knowledge risks being obscured. Many researchers, practitioners and managers have dismissed the plain repurposing of news content between different proprietary platforms, stressing journalism must be developed and customized in harmony with the affordances of the distinct medium or platform for which it will be published (Westlund, 2013).

Contemporary news producers face the possibilities of publishing for a multitude of both proprietary and nonproprietary platforms. However large investments are required to successfully customize news content and services for all platforms, and thus it can make sense to step back and produce platform-agnostic news. This means that content produced is not dedicated to one specific platform, but instead harmonizes with as many platforms as possible: from proprietary news sites and apps, to voice-driven smart speakers, car instrument panels, and so forth. Few have the resources to do so. Yet, publishing news for non-proprietary platforms involves a loss of control. With social media, news producers cannot control the publishing context: how the news material is presented, the type and quality of potential adjacent information, and the potential engagement that develops around it (i.e., clicks, comments, re-tweets, sharing). Consequently, anyone or anything producing news for social media may want to embed meta-communication indicating original principles: truth claims, information on the nature of the material, the journalistic process, and who the producer is (company, journalist, robot, etc.). With increasingly sophisticated methods and tools for creating and publishing mock news, it is important for producers of journalistic news to embed clearly recognizable metacommunication, including font, angles, introductory music, watermarks, logotypes, etc. in video, or embedding key clarification in headline or preamble in texts.
Third, while social media facilitate the communication of opinions, personal voices, or even speculation, they also contribute to the effective dissemination of "fake" or "mock news", and the related deception of truth claims (Tandoc, Lim, et al., 2018). Mock is a concept connoting artifice, mimicry, imitation, as well as being fake and bad; thus, the practice of imitating the tone and appearance of news material, comprised of intentionally fake content. Characteristic of these is the exploitation of the conventionalized forms of news and the related discourse of factuality to disseminate fabricated news and false information. The principle behind the information is masked. The purpose of doing so is often linked to political and/or economic interests. Since "fake news" simply connotes something being fake, we therefore propose the concept of "mock news" because of its two-fold meaning also involving the imitation of how news material is presented. Metaphorically, mock news is like a chameleon, successful in camouflaging and blending into their context through skin coloration that imitates their surroundings. So-called "deep fakes" have emerged quite explicitly doing this by technically manipulating voices and faces, giving the impression that a specific person says something they did not. Thus, the dislocation of news in social media and the traveling of decontextualized news between different platforms involve a refashioning as well as obscured and pure fraud regarding truth claims. This implies a destabilization concerning the authority of journalism and news as a form of knowledge (Carlson, 2017), which creates challenges for professional journalists and news organizations promising to provide reliable news, as well as for audiences who ultimately have to decide what to trust.

\subsection{Production of Knowledge and the 'Contexts of Justification'}

The dislocation of news journalism in social media has significant implications for the knowledge-producing practices within journalism and related processes of justification (Ekström \& Westlund, 2019). It is critical for research to reopen the critical epistemological questions of "how journalists know what they know" and what qualifies as justified facts in particular contexts (Ettema \& Glasser, 1985). Adopting a sociological approach, epistemology refers to knowledge-producing practices, the norms, standards, methods and classifications enacted in the processing of facts and the justifications of truth claims (Ekström, 2002). The primary question posed is therefore not whether particular news is true or not, but what characterizes the practical ways of dealing with knowledge and facts in news production (Godler \& Reich, 2013). How do journalists decide what is sufficiently justified to publish in concrete situations?

This sociological approach understands the processing of facts and the justification of news as practical matters handled through norms and standards developed within a particular context; this has been defined as "the 
context of justification" (Ettema \& Glasser, 1985). This social constructivist position does not imply a radical form or constructivism and relativism (Ekström \& Westlund, 2019; Godler \& Reich, 2013, p. 674). It is a moderate form of constructivism (Elder-Vass, 2012, pp. 8, 230). News is dependent on how journalists collectively understand and produce knowledge about a world, one which exists independent of journalism. All news accounts are not equally true or fallible, and collective norms and standards become important objects of inquiry solely because they effect news journalists' validations of facts and their justifications of truth claims.

With the transformations of news production in online and social media, the contexts of justification, and related norms and standards, are changing and vary far more than seminal studies on daily news and investigative reporting captured. There has been much hope and hype around the potential of social media for how journalists can further develop news work, for instance, by turning to a much larger pool of sources (for a critical review, see Lewis \& Molyneaux, 2018). A critical aspect concerns the processing (selections, evaluations and authorization) of sources, as established journalist-source relationships and the relatively shared understanding of sources within newsrooms are central to the epistemology of news. With numerous social media platforms readily available, journalists now engage in the practice of lurking in personal accounts, groups, pages and so forth. Sometimes they utilize the information found in the news. On other occasions, journalists may identify relevant sources or ideas for investigations through social media, and then take this with them into their subsequent news work. With the regular use of social media sources, routines in the assessment of sources, and the categorizations of sources providing either pre-justified facts or facts that require careful cross-checking are potentially destabilized. Journalists have to update their standards and skills in assessing different voices in social media. It is a particular challenge for journalists to verify the identity and credibility of the voices behind potentially newsworthy information.

While journalists in some contexts publish tweets without any forms of verification, there are also contexts in which journalists are generally reluctant to use social media sources (Broersma \& Graham, 2013, p. 461). The dominance of elite sources, and the related hierarchy of authorized sources in news journalism (BelairGagnon, 2015; Lecheler \& Kruikemeier, 2016; van Leuven et al., 2018), is reproduced in the more frequent use of Twitter (compared to Facebook), the platform typically used by politicians, celebrities, etc. Thus, they provide a constant stream of newsworthy and quotable utterances (von Nordheim, Boczek, \& Kroppers, 2018). As Duffy and Tan Rui Si (2018) note, there is a contradiction in journalism between the potential benefits of using the diversity of non-elite voices in online and social media to enrich journalism, and the "practicalities of the demand for speed, accuracy and validation". This can lead to a tendency of favoring official elite sources, as the identity of non-elite voices is considered more demanding and time-consuming to verify within an ever-faster news cycle where the risk of incorrect data being published increases (Karlsson, Clerwall, \& Nord, 2017). This also necessitates an adjustment of shared verification standards, and the validation of news tends to be reduced to the accuracy of bits of information, individual facts and quotes (Undurraga, 2017). The expectations of fast publishing also shape the already challenging sourcing practices (Eldridge \& Bødker, 2018), and reduces the time for cross-checking. Some exceptions occur, such as with live blogging, in which journalists turn to a larger and more diverse set of sources (Thorsen \& Jackson, 2018). Moreover, journalists may also engage in mobile sourcing via chat apps (Belair-Gagnon, Agur, \& Frisch, 2018), and messaging apps like WhatsApp to successfully invite people to participate in the news production processes (KliglerVilenchik \& Tenenboim, in press).

While at the selection and filtering stage, journalists have typically maintained control, rarely allowing others to participate in or influence the news production processes, the dislocation of news does have significant implications regarding the context of justification external to the newsroom and news journalism. As news is increasingly distributed in the form of decontextualized pieces of information (Nielsen, 2017), it is both detached from its original context of production and justified in a new context: what is published in authorized media or by authorized voices is sufficiently true to be distributed, if there are no obvious reasons for not doing so. In these republishing processes, the responsibility for verifications is reallocated and the risk of problematic truths being circulated increases, not least because this circulation often occurs at a fast speed.

Platform companies, thus, house the distribution of news of various quality and truthfulness. Various actors can produce and publish news on a recurrent basis, or as random acts of journalism. The varied platform companies do not take the same responsibility for the content published as news media companies do. It has been widely acknowledged that Facebook has significant power and control over what people see and are influenced by, thus, acting in an editorial manner. Yet, Facebook has largely avoided the expenses of manual editing and curation, only tweaking its algorithms, and invited external and public fact-checking to counter scandals. To what extent this process of accountability will result in any changes of significant implications for the validation and justification of news in social media is still an open question.

\subsection{Audiences' Acceptance/Rejections of Knowledge Claims}

In the examination of news as knowledge and justified beliefs, one must also ask what makes particular forms of news justified from the audience's point of view. The jus- 
tification of news as valid knowledge includes audience activities on three aspects: general trust, patterns of consumption and critical evaluations. Audiences attribute different levels of trust/distrust to different news providers, with implications for their news consumption as well as their inclination to accept the truth claims of individual news items. News consumption is typically embedded in everyday practices. Forms of news are accepted or rejected as valid knowledge about current events in the way they are actually consumed and prioritized. The patterns of clicking and sharing digital news, for example, validate particular forms of news, whether intentional or not. How news organizations understand their authority as truth-tellers, and more specifically, the relevance of individual news items, is dependent on audience feedback increasingly measured through audience metrics (Zamith, 2018). Taken together, audiences' preunderstandings of the principles behind the news and their habitual forms of news consumption mean they do not need to critically assess individual news, if they do not have particular reasons to doubt its veracity (Tandoc, Ling, et al., 2018, pp. 3-4). How the three aspects of trust, patterns of consumption and critical evaluations are interrelated is a key issue in current research (e.g., Fletcher \& Park, 2017). Schwarzenegger (in press) propose the concept "personal epistemologies" to analyze how individuals navigate their media use and interact with the news based on perceived credibility and conceptions of knowledge and knowing.

Critical evaluations include more specific activities of assessing the veracity of news and identifying biases and misinformation. The critical evaluations of news in social media have been explained in relation to internal activities based on people's own knowledge and interpretation of the news, and external activities of checking with trusted people and sources (Tandoc, Ling, et al., 2018; see also Edgerly, 2017). Not surprisingly, audiences' perceptions of, and abilities to detect, fake or mock news in social media have attracted increasing scholarly interest (Newman et. al. 2018; Schwarzenegger, in press). Zubiaga and Ji (2014) suggest that the verification of information in social media and the identification of fake news is dependent on interpretations of the authority of the author behind the information, plausibility, how information is presented, as well as the processes of independent corroboration. Audiences' critical evaluations are conditioned by several aspects of dislocated news, such as the sometimes-obscured principle behind the news and the diversity of actors producing news with both sincere and dark intentions (Quandt, 2018). When news is detached from its original context, it may become more difficult, and sometimes even impossible, for audiences to evaluate it based on the trust and authority of the original producer. Clearly, many news publishers do their best to ensure their brand remains visible in conjunction to how a piece of news is published. However, they are not in control of how social media platforms choose to display content and brands, and may have little influence over this unless they pay them.
Important to note, audiences' justification of newsacceptance or rejection of knowledge claims-involves cognitive, discursive and social dimensions. Regarding the latter, the dislocation of news has significant implications for the social context and practices in which news is justified. Research has analyzed mechanisms with potentially counteracting effects on the critical reading of news. Mechanisms for the selective exposure of news in social media, on the one hand, tend to increase the effects of well-known biases in justifications related to beliefs and values. News is authorized as relatively reliable and valuable knowledge in peer networks, political groups, etc. On the other hand, social media platforms have contributed to more distributed and collaborative processes of justification in which audiences can compare information from different sources; produce and share supplementary and corrective information, critical readings and knowledge about false messages, to some extent also functioning as constructive feedback for news journalism (Hermida, 2012).

The role of audiences in the justification of news is not restricted to the assessment of individual news items. News is also accepted or rejected in the acts of sharing on personal networks, sometimes with the effect that news goes viral. Social media platforms have enabled and spurred audiences to actively participate in different ways such as linking news articles to their Facebook news feeds or tweeting about the news. Audiences also use social media platforms to engage in discussions, by commenting on news articles and responding to other people's comments. Consequently, interpersonal relationships have become increasingly important in the validation of news. "Personal influence" (Katz \& Lazarsfeld, 1955) of the individuals publishing or sharing news is increasingly integrated into the news as a form of authoritative knowledge, worth listening to and trusting in.

\section{Conclusion}

Institutional news publishers have long comprised the producers of journalism. They published and distributed their news via proprietary platforms. Social media platforms now act as intermediaries. Consequently, they have caused disruption, increasingly dislocating the news producers and their news production processes from the platforms onto which the news material is published and where it is accessed. Ultimately, a dislocation of news journalism is occurring in which news publishers have become dependent, to varying degrees, on platforms nonproprietary to themselves, provided by social media companies. As discussed, building off of the argument forward by Emerson (1962), finding a situation in which actor I (e.g., news media) depend on actor II (e.g., platform companies) for achieving the goals they have set is a strong indicator of power. It plays out in many ways; for gaining wide reach and engagement with news, building and sustaining revenue, implementing analytics to gain metrics that are useful or improving different forms 
of digital journalism. While dislocation of news journalism mainly involves a process of dislocation from news media organizations towards platform companies, this conceptualization also covers processes in which news organizations work towards reducing their dependence and developing the significance of their proprietary platforms again (Chua \& Westlund, 2019; Newman, 2019). It is worth considering news organizations struggling to finance their operations may establish fruitful partnerships if they can offer digital platforms of their own. These can also serve as the most important appeal for potential buyers who may have to come to their rescue in the future.

The dislocation of news journalism has important implications for how news journalism achieves the epistemic goals of providing reliable public information. Challenges and disruption of the truth claims of news and the authority of news journalism have been discussed most intensively in relation to the discourse of so-called fake news. However, the transformation of news in the context of social media has also spurred research focusing on epistemology related issues. Researchers have, for example, analyzed the competing and obscured knowledge claims in the distribution of news in social media, the shifting processing and justifications of sources in journalism, and the role of social media in restructuring the social contexts in which audiences assess, interpret and validate the news.

With ambitions toward contributing to this emerging sub-field of "epistemologies of digital journalism", this article has presented a broad perspective of the epistemological implications regarding the dislocation of news journalism. The approach proposed differentiates between (1) articulated knowledge and truth claims, (2) the production and justification of knowledge in journalism (3) the acceptance/rejection of knowledge claims in audience activities. This approach helps to systematically analyze key aspects of epistemology, and integrate current research on various epistemological practices.

A general argument proposed in this article concerns how truth claims and practices of justification, and ultimately the authority of news and journalistic knowledge, must be understood in relation to how non-proprietary social media platforms disrupt the distribution, production and consumption of proprietary news. What also becomes clear is that existing mechanisms pull in different directions, resulting in upgraded and downgraded truth claims; increased transparency and obfuscation of production principles; sophisticated and limited practices of justification in news production; collaborative activities that shape audiences' critical assessments of news and network-based audience activities that uncritically reproduce unverified and false news. However, the dislocation of news journalism seems to indicate that the justification of journalistic truth and knowledge claims is increasingly dependent on activities beyond the control of the news media. An important challenge for future research is to investigate how the various epistemolog- ical practices in news production and news consumption are related to the more general authority and legitimacy of news journalism as forms of knowledge, in the context of the ongoing transformations of digital journalism and platforms.

\section{Acknowledgments}

First, we wish to thank Scott Eldridge II and Marcel Broersma, who went beyond our expectations in their engagement with our article as academic editors. We are truly grateful for all of your comments helping advance our article in terms of argument, clarity and focus. Second, we thank James Katz for his worthwhile feedback earlier on in the process. Third, we thank the Swedish Foundation for Humanities and Social Science for providing us the resources to author this article for our "Epistemologies of Digital Journalism" project.

\section{Conflict of Interests}

The authors declare no conflict of interests.

\section{References}

Anderson, C. W., \& Revers, M. (2018). From counterpower to counter-Pepe: The vagaries of participatory epistemology in a digital age. Media and Communication, 6(4), 24-35. https://doi.org/10.17645/ mac.v6i4.1492

Andersson Schwarz, J. (2017). Platform logic: An interdisciplinary approach to the platform-based economy. Policy and Internet, 9(4), 374-394.

Belair-Gagnon, V. (2015). Social media at the BBC. London: Routledge.

Belair-Gagnon, V., Agur, C., \& Frisch, N. (2018). Mobile sourcing: A case study of journalistic norms and usage of chat apps. Mobile Media \& Communication, 6(1), 53-70.

Bell, E., Owen, T., Brown, P., Hauka, C., \& Rashidian, N. (2017). The platform press-How Silicon Valley reengineered journalism. New York, NY: Tow Center for Digital Journalism.

Benton, J. (2018). Facebook's message to media: "We are not interested in talking to you about your traffic....That is the old world and there is no going back". NiemanLab. Retrieved from http://www.niemanlab. org/2018/08/facebooks-message-to-media-we-arenot-interested-in-talking-to-you-about-your-trafficthat-is-the-old-world-and-there-is-no-going-back

Borger, M., van Hoof, A., Costera Meijer, I., \& Sanders, J. (2013). Constructing participatory journalism as a scholarly object. Digital Journalism, 1(1), 117-134. https://doi.org/10.1080/21670811.2012.740267

Broersma, M., \& Graham, T. (2013). Twitter as a news source: How Dutch and British newspapers used tweets in their news coverage, 2007-2011. Journalism Practice, 7(4), 446-464. 
Bruns, A. (2018). Gatewatching and news curation: Journalism, social media, and the public sphere. New York, NY: Peter Lang.

Carlson, M. (2016). Metajournalistic discourse and the meanings of journalism: Definitional control, boundary work, and legitimation. Communication Theory, 26(4), 349-368.

Carlson, M. (2017). Journalistic authority: Legitimating news in the digital era. New York, NY: Columbia University Press.

Carlson, M. (2018a). Confronting measurable journalism. Digital Journalism, 6(3), 406-417.

Carlson, M. (2018b). Automating judgment? Algorithmic judgment, news knowledge, and journalistic professionalism. New Media \& Society, 20(5), 1755-1772. https://doi.org/10.1177/1461444817706684

Carlson, M., \& Lewis, S. C. (Eds.). (2015). Boundaries of journalism: Professionalism, practices and participation. Abingdon and New York: Routledge.

Carlson, M., Robinson, S., Lewis, S. C., \& Berkowitz, D. A. (2018). Journalism studies and its core commitments: The making of a communication field. Journal of Communication, 68(1), 6-25. https://doi.org/10.1093/ joc/jqx006

Chua, S., \& Westlund, O. (2019). Audience-centric engagement, collaboration culture and platform counterbalancing: A longitudinal study of ongoing sensemaking of emerging technologies. Media and Communication, 7(1), 153-165.

Deuze, M., \& Witschge, T. (2017). Beyond journalism: Theorizing the transformation of journalism. Journalism. https://doi.org/10.1177/1464884916688550

DeVito, M. A. (2017). From editors to algorithms. Digital Journalism, 5(6), 753-773. https://doi.org/10.1080/ 21670811.2016.1178592

Duffy, A., \& Tan Rui Si, J. (2018). Naming the dog on Internet: Student reporter's verification tactics for non-elite newsmakers online. Digital Journalism, 6(7), 910-927. https://doi.org/10.1080/ 21670811.2017.1377092

Edgerly, S. (2017). Seeking out and avoiding the news media: young adults' proposed strategies for obtaining current events information. Mass Communication and Society, 20(3), 358-377.

Ekström, M. (2002). Epistemologies of TV journalism: A theoretical framework. Journalism, 3(3), 259-282. https://doi.org/10.1177/146488490200300301

Ekström, M., \& Westlund, O. (2019). Epistemology and journalism. In Oxford encyclopedia of journalism studies. Oxford: Oxford University Press. http://dx. doi.org/10.1093/acrefore/9780190228613.013.806

Elder-Vass, D. (2012). The reality of social construction. New York, NY: Cambridge University Press.

Eldridge, S., \& Bødker, H. (2018). Negotiating uncertain claims. Journalism Studies, 19(13), 1912-1922.

Eldridge, S., \& Franklin, B. (2017). Introduction: Defining digital journalism studies. In B. Franklin \& S. Eldridge (Eds.), The Routledge companion to digital journalism studies. Abingdon: Routledge

Eldridge, S., \& Franklin, B. (2019). Introducing the complexities of developments in digital journalism studies. In S. Eldridge \& B. Franklin (Eds.), The Routledge handbook of developments in digital journalism studies. Abingdon: Routledge.

Eldridge, S., Hess, K., Tandoc, E. C., Jr., \& Westlund, O. (in press). Navigating the scholarly terrain: Introducing the digital journalism compass. Digital Journalism, $7(3)$.

Emerson, R. M. (1962) Power-dependence relations. American Sociological Review, 27(1), 31-41.

Ettema, J. S., \& Glasser, T. L. (1985). On the epistemology of investigative journalism. Communication, 8, 183-206. Retrieved from https://www. researchgate.net/publication/234722548_On_the_ Epistemology_of_Investigative_Journalism

Fletcher, R., \& Park, S. (2017). The impact of trust in the news media on online news consumption and participation. Digital Journalism, 5(10), 1281-1299.

Gillespie, T. (2018). Custodians of the Internet: Platforms, content moderation, and the hidden decisions that shape social media. New Haven, CT: Yale University Press.

Godler, Y., \& Reich, Z. (2013). How journalists think about facts. Journalism Studies, 14(1), 94-112. https://doi.org/10.1080/1461670X.2012.689489

Graves, L., \& Anderson, C. W. (in press) Discipline and promote: Building infrastructure and managing algorithms in a 'structured journalism' project by professional fact-checking groups. New Media \& Society.

Hågvar, Y. B. (2019). News media's rhetoric on Facebook. Journalism Practice. https://doi.org/10.1080/ 17512786.2019.1577163

Hanitzsch, T. (2007). Deconstructing journalism culture: Toward a universal theory. Communication Theory, 17(4), 367-385.

Hermida, A. (2012). Tweets and truth. Journalism Practice, 6(5/6), 659-668.

Holt, K. (2018). Alternative media and the notion of antisystemness: Towards an analytical framework. Media and Communication, 6(4), 49-57.

Hutchby, I. (2011). Doing non-neutral: Belligerent interaction in the hybrid political Interview. In M. Ekström \& M. Patrona (Eds.), Talking politics in broadcast media (pp. 115-134). Amsterdam: John Benjamins.

Karlsson, M. (2011). The immediacy of online news, the visibility of journalistic processes and a restructuring of journalistic authority. Journalism, 12(3), 279-295.

Karlsson, M., Clerwall, C., \& Nord, L. (2017). Do not stand corrected: Transparency and users attitudes to inaccurate news and correction in online journalism. Journalism and Mass Communication Quarterly, 94(1), 148-167.

Katz, E., \& Lazarsfeld, P. F. (1955). Personal influence: The part played by people in the flow of mass communications. New York, NY: Free Press.

Kim, Y., Chen, H. T., \& Gil De Zúñiga, H. (2013). Stum- 
bling upon news on the Internet: Effects of incidental news exposure and relative entertainment use on political engagement. Computers in Human Behavior, 29(6), 2607-2614. https://doi.org/10.1016/ j.chb.2013.06.005

Kligler-Vilenchik, N., \& Tenenboim, O. (in press). Sustained journalist-audience reciprocity in a mesonewspace: The case of a journalistic WhatsApp group. New Media \& Society.

Konow-Lund, M., Benestad Hågvar, Y., \& Olsson, E. K. (2018). Digital innovation during terror and crisis. Digital Journalism. https://doi.org/10.1080/ 21670811.2018.1493937

Lecheler, S., \& Kruikemeier, S. (2016). Re-evaluating journalistic routines in a digital age: A review of research on the use of online sources. New Media \& Society, 18(1), 156-171.

Lewis, S. C. (2012). The tension between professional control and open participation. Information, Communication \& Society, 15(6), 836-866. https://doi.org/ 10.1080/1369118X.2012.674150

Lewis, S. C., \& Westlund, O. (2015a). Big data and journalism: Epistemology, expertise, economics, and ethics. Digital Journalism, 3(3), 447-466. https://doi.org/ 10.1080/21670811.2014.976418

Lewis, S. C., \& Westlund, O. (2015b). Actors, actants, audiences, and activities in cross-media news work. Digital Journalism, 3(1), 19-37.

Lewis, S., \& Molyneux, L. (2018). A decade of research on social media and journalism: Assumptions, blind spots, and a way forward. Media and Communication, 6(4), 11-23.

Matheson, D., \& Wahl-Jorgensen, K. (in press). The epistemology of live blogging. New Media \& Society.

Montgomery, M. (2007). The discourse of broadcast news: A linguistic approach. Abingdon and New York: Routledge.

Myllylahti, M. (2018). An attention economy trap? An empirical investigation into four news companies' Facebook traffic and social media revenue. Journal of Media Business Studies. https://doi.org/10.1080/ 16522354.2018.1527521

Newman, N. (2019). Journalism, media and technology trends and predictions 2019. Oxford: Reuters Institute for the Study of Journalism.

Newman, N., Fletcher, R., Kalogeropoulos, A., Levy, A. K., \& Nielsen, R. K. (2018). Reuters Institute digital news report 2018. Oxford: Reuters Institute for the Study of Journalism.

Nielsen, R. K. (2017). Digital news as forms of knowledge: A new chapter in the sociology of knowledge. In P. Boczkowski \& C. W. Anderson (Eds.), Remaking the news essays on the future of journalism scholarship in the digital age (pp. 1-27). Cambridge, MA: MIT Press.

Nielsen, R. K, \& Ganter, S. A. (2018). Dealing with digital intermediaries: A case study of the relations between publishers and platforms. New Media \& Society, 20(4), 1600-1617.
Ohlsson, J., \& Facht, U. (2017). Ad wars. Gothenburg: Nordicom.

Picard, R. G. (2014). Twilight or new dawn of journalism? Digital Journalism, 2(3), 273-283.

Quandt, T. (2018). Dark participation. Media and Communication, 6(4), 36-48.

Robinson, S., Lewis, S. C., \& Carlson, M. (in press). Locating the 'digital' in digital journalism studies: Transformations in research. Digital Journalism, 7(3).

Salgado, S., \& Strömbäck, J. (2012). Interpretive journalism: A review of concepts, operationalizations and key findings. Journalism, 13(2), 144-161.

Schwarzenegger, C. (in press). Personal epistemologies of the media: Selective criticality, pragmatic trust, and competence confidence in navigating media repertoires in the digital age. New Media \& Society.

Sehl, A., Cornia, A., \& Nielsen, R. K. (2018). Public service news and social media. Oxford: Reuters Institute for the Study of Journalism.

Steensen, S., \& Ahva, L. (2015). Theories of journalism in a digital age. Digital Journalism, 3(1), 1-18. https://doi.org/10.1080/21670811.2014.927984

Steensen, S., Larsen, A. M., Hågvar, Y., \& Fonn, B. (in press). What does digital journalism studies look like? Digital Journalism, 7(3).

Tandoc, E. C., Jr., Lim, Z. W., \& Ling, R. (2018). Defining "fake news". Digital Journalism, 6(2), 137-153. https://doi.org/10.1080/21670811.2017.1360143

Tandoc, E. C., Jr., Ling, R., Westlund, O., Duffy, A., Goh, D., \& Zheng Wei, L. (2018). Audiences' acts of authentication in the age of fake news: A conceptual framework. New Media \& Society, 20(8), 2745-2763. https://doi.org/10.1177/1461444817731756

Thorsen, E., \& Jackson, D. (2018). Seven characteristics defining online news formats: Towards a typology of online news and live blogs. Digital Journalism, 6(7), 847-868.

Thurman, N., \& Walters, A. (2013). Live blogging: Digital journalism's pivotal platform? Digital Journalism, 1(1), 82-101. https://doi.org/10.1080/ 21670811.2012.714935

Undurraga, T. (2017). Knowledge-production in journalism: Translation, mediation and authorship in Brazil. The Sociological Review, 66(1), 58-74. https:// doi.org/10.1177/0038026117704832

Usher, N. (2018). Breaking news production processes in US metropolitan newspapers: Immediacy and journalistic authority. Journalism, 19(1), 21-36. https://doi.org/10.1177/1464884916689151

Van Leuven, S., Kruikemeier, S., Lecheler, S., \& Hermans, L. (2018). Online and newsworthy: Have online sources changed journalism? Digital Journalism, 6(7), 798-806.

Von Nordheim, G., Boczek, K., \& Koppers, L. (2018). Sourcing the sources: An analysis of the use of Twitter and Facebook as a journalistic source over 10 years in The New York Times, The Guardian, and Suddeutsche Zeitung. Digital Journalism, 6(7), 807-828. 
https://doi.org/10.1080/21670811.2018.1490658

Westlund, O. (2011). Cross-media news workSensemaking of the mobile media (r)evolution. Gothenburg: JMG, University of Gothenburg.

Westlund, O. (2013). Mobile news. Digital Journalism, 1(1), 6-26. https://doi.org/10.1080/ 21670811.2012.740273

Westlund, O., \& Ekström, M. (2018). News and participation through and beyond proprietary platforms in an age of social media. Media and Communication, 6(4), 1-10. https://doi.org/10.17645/mac.v6i4.1775

Westlund, O., \& Ekström, M. (2019). News organizations: Knowledge, routines and coordination. In K. WahlJorgensen \& T. Hanitzsch (Eds.), Handbook of journal- ism studies. London: Routledge.

$\mathrm{Wu}, \mathrm{S}$. (2018). The disruption of social media-How the traditional collaborative model between reporters and editors evolves in American newsrooms. Digital Journalism, 6(6), 777-797.

Zamith, R. (2018). Quantified audiences in news production. A synthesis and research agenda. Digital Journalism, 6(3), 418-435. https://doi.org/10.1080/ 21670811.2018.1444999

Zubiaga, A., \& Ji, H. (2014). Tweet but verify: Epistemic study of information verification on Twitter. Social Network Analysis and Mining, 4(1). https://doi.org/ 10.1007/s13278-014-0163-y

\section{About the Authors}

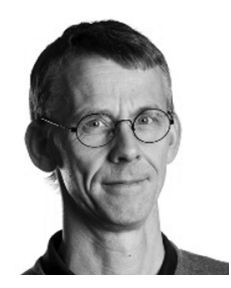

Mats Ekström (PhD) is Professor at the Department of Journalism, Media and Communication at the University of Gothenburg. His research focuses on journalism, media discourse, conversation in institutional settings, political communication and young people's political engagement. Recent publications include "Right-wing populism and the dynamics of style" (Palgrave Communications, 2018, with Marianna Patrona and Joanna Thornborrow); "Social media, porous boundaries, and the development of online political engagement among young citizens" (New Media \& Society, 2018, with Adam Shehata) and The Mediated Politics of Europe: A Comparative Study of Discourse (Palgrave, 2017, with Julie Firmstone).

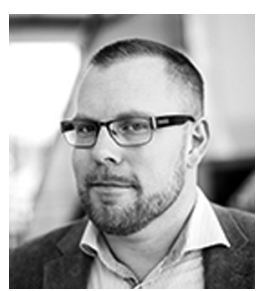

Oscar Westlund (PhD) is Professor at the Department of Journalism and Media Studies at Oslo Metropolitan University, where he leads the OsloMet Digital Journalism Research Group. He holds secondary appointments at Volda University College and University of Gothenburg. Westlund specializes in journalism, media management and news media consumption for proprietary news media platforms such as news sites and mobile applications, as well as with regards to social media platforms. Westlund is the Editor-in-Chief of Digital Journalism, and has also edited special issues for several other leading international journals. He currently leads a research project called the epistemologies of digital news production, funded by the Swedish Foundation for Humanities and Social Sciences. 